Ethos: Jurnal Penelitian dan Pengabdian kepada Masyarakat, Vol 8, No.1, Juni 2019: 132-138

\title{
Pengembangan Website Profile PMi Kota Tarakan Sebagai Sarana KeterbukaAn Informasi Publik
}

\section{${ }^{1}$ Muhammad, ${ }^{2}$ Muhammad Fadlan, ${ }^{3}$ Muhammad Hafid, ${ }^{4}$ Muhammad Iqbal Fahreza}

\author{
${ }^{1,2,3,4}$ Program Studi Sistem Informasi, STMIK PPKIA Tarakanita Rahmawati, Jl. Yos Sudarso No. 8. \\ email: ${ }^{1}$ muhammad@ppkia.ac.id; ${ }^{2}$ fadlan@ppkia.ac.id
}

\begin{abstract}
One impact of the development of information technology is the use of websites as a medium to facilitate the dissemination of information. One type of website that is widely used by government agencies, education, industry and public organizations is a website profile. Palang Merah Indonesia (PMI) Kota Tarakan is one of the public organizations engaged in humanity in Tarakan City. Current conditions, PMI Kota Tarakan does not yet have a media information in the form of a website that can be used to disseminate various information related to PMI Kota Tarakan activities to the public, so a process of developing a profile website for the PMI Kota Tarakan is needed. The main objective of this community service activity is to produce a PMI Kota Tarakan Profile Website to support the PMI Kota Tarakan. Website development process is done by using PHP (PHP: Hypertext Preprocessor) as a scripting language and MySQL as a database server. The final result of community service activities in terms of developing this website is a website that is able to provide convenience for the PMI Kota Tarakan in terms of providing information to the public, specifically related to the activities carried out by the PMI Kota Tarakan.
\end{abstract}

Keywords: information, PMI, Tarakan, website

\begin{abstract}
Abstrak. Salah satu dampak dari berkembangnya teknologi informasi adalah pemanfaatan website sebagai salah satu media untuk memudahkan dalam menyebarkan sebuah informasi. Salah satu jenis website yang banyak digunakan baik oleh instansi pemerintahan, pendidikan, industri maupun organisasi publik adalah website profile. Palang Merah Indonesia (PMI) Kota Tarakan merupakan salah satu organisasi publik yang bergerak dibidang kemanusiaan yang ada di Kota Tarakan. Kondisi yang ada saat ini, PMI Kota Tarakan belum memiliki media informasi berupa website yang dapat digunakan untuk menyebarkan berbagai informasi terkait dengan kegiatan PMI Kota Tarakan kepada masyarakat, sehingga dibutuhkan sebuah proses pengembangan terhadap website profile bagi PMI Kota Tarakan. Tujuan utama dari kegiatan pengabdian masyarakat ini adalah menghasilkan sebuah Website Profile PMI Kota Tarakan untuk mendukung PMI Kota Tarakan. Proses pengembangan website dilakukan dengan menggunakan PHP (PHP: Hypertext Preprocessor) sebagai bahasa scripting dan MySQL sebagai database server. Hasil akhir dari kegiatan pengabdian masyarakat dalam hal pengembangan website ini adalah sebuah website yang mampu memberikan kemudahan bagi pihak PMI Kota Tarakan dalam hal memberikan informasi kepada masyarakat, khususnya terkait dengan kegiatan-kegiatan yang dilakukan oleh PMI Kota Tarakan.
\end{abstract}

Kata kunci: informasi, PMI, tarakan, website.

\section{Pendahuluan}

Informasi merupakan salah satu aspek penting dalam era digital. Setiap organisasi dituntut untuk mampu mengelola dan memanfaatkan setiap informasi yang ada dengan maksimal (Febrianingsih, 2012). Selain itu, organisasi juga dituntut untuk dapat menyediakan informasi dengan cepat, 
relevan dan akurat (Santoso, Minarwati, \& Kholidun, 2019).

Salah satu poin penting terkait dengan pengelolaan informasi adalah menyebarkan informasi organisasi kepada masyarakat luas. Informasi tersebut dapat berupa berbagai kegiatan yang telah dilakukan bagi institusi / organisasi publik, atau dapat juga berupa informasi produk unggulan bagi perusahaan yang bergerak dibidang industri. Banyak cara yang dapat digunakan untuk menyebarkan informasi kepada masyarakat luas, salah satunya adalah dengan memanfaatkan perkembangan teknologi informasi yang kian pesat.

Salah satu dampak dari berkembangnya teknologi informasi adalah pemanfaatan website sebagai salah satu media untuk menyebarkan informasi. Perkembangan website saat ini demikian cepat, hal ini disebabkan oleh perkembangan infrastruktur yang cukup pesat di bidang teknologi informasi, seperti internet. Akhir-akhir ini, berbagai jenis institusi, organisasi maupun lembaga telah banyak yang menggunakan website sebagai salah satu media untuk menyalurkan informasi (Suhartanto, 2012).

Website merupakan sebuah aplikasi yang berisikan dokumendokumen multimedia (teks, gambar, suara, animasi, video) di dalamnya, yang menggunakan protokol HTTP (hypertext transfer protocol) dan untuk mengakses sebuah halaman website dapat menggunakan perangkat lunak yang disebut dengan browser (Suhartanto, 2012). Banyak manfaat yang dapat diambil dari penggunaan sebuah website. Bagi jurnalis misalnya, informasi dan data di website dapat digunakan sebagai data awal sebelum melakukan liputan langsung di lapangan. Pengusaha berharap website dapat mempromosikan potensi lokal kepada masyarakat luas. Demikian pula bagi akademisi dapat memanfaatkan data dan informasi yang ditampilkan di website untuk memenuhi kebutuhan mereka (Wiratmo, Irfan, \& Kuwatono, 2017).

Salah satu jenis website yang banyak digunakan baik oleh instansi pemerintahan, pendidikan, industri maupun organisasi publik adalah website profile. Melalui website ini, berbagai institusi maupun organisasi dapat menyebarkan informasi terkait dengan institusi atau organisasi masingmasing kepada masyarakat. Hal ini sejalan dengan salah satu prinsip utama yang harus dimiliki oleh sebuah instansi maupun organisasi, yaitu prinsip keterbukaan informasi.

Palang Merah Indonesia (PMI) Kota Tarakan merupakan salah satu organisasi publik yang ada di Kota Tarakan dan bergerak dibidang kemanusiaan. Organisasi ini didirikan pada tanggal 8 Oktober 1997 (Hafid, 2018).

Berdasarkan, kondisi yang ada saat ini, PMI Kota Tarakan belum memiliki media informasi berupa website yang dapat digunakan untuk menyebarkan berbagai informasi terkait dengan kegiatan PMI Kota Tarakan kepada masyarakat. Sehingga, pihak PMI Kota Tarakan belum mampu menjangkau masyarakat luas untuk memberikan informasi terkait dengan PMI Kota Tarakan. Berdasarkan hal tersebut, maka pada kegiatan pengabdian ini dilakukan sebuah pengembangan website profile untuk PMI Kota Tarakan. Diharapkan melalui website yang dikembangkan dapat membuat pihak PMI mudah dalam memberikan informasi kepada masyarakat terkait dengan kegiatan maupun berbagai informasi penting dari PMI Kota Tarakan.

Tujuan utama dari kegiatan ini adalah menghasilkan sebuah Website Profile PMI Kota Tarakan untuk mendukung PMI Kota Tarakan dalam 
memberikan berbagai informasi kepada masyarakat kota Tarakan. Diharapkan melalui website yang dikembangkan dapat membuat pihak PMI menjadi mudah dalam memberikan informasi kepada masyarakat terkait dengan kegiatan maupun informasi penting dari PMI Kota Tarakan.

\section{Metode Penelitian}

Kegiatan pengabdian masyarakat dalam rangka pengembangan Website Profile ini dilakukan dikantor Palang Merah Indonesia (PMI) Kota Tarakan, yang terletak di Jalan Pulau Irian No. 40, Kelurahan Kampung Satu Skip, Kecamatan Tarakan Tengah, Kota Tarakan, Provinsi Kalimantan Utara.

Dalam pelaksanaan kegiatan pengabdian ini terdapat beberapa tahapan yang dilalui. Tahapan-tahapan pengabdian terkait dengan pengembangan Website Profile di Palang Merah Indonesia (PMI) Kota Tarakan. Tahapan ini diperlukan agar pelaksanaan kegiatan dapat dilakukan secara sistematis, sehingga dapat memudahkan tim pelaksana dalam menyelesaikan seluruh rangkaian kegiatan yang akan dilakukan. Secara keseluruhan, tahapan tersebut dapat dilihat pada Gambar 1.

Pada Gambar 1, dapat dilihat terdapat 6 (enam) tahapan utama dalam melakukan kegiatan pengabdian masyarakat dalam hal pengembangan website profile PMI Kota Tarakan.

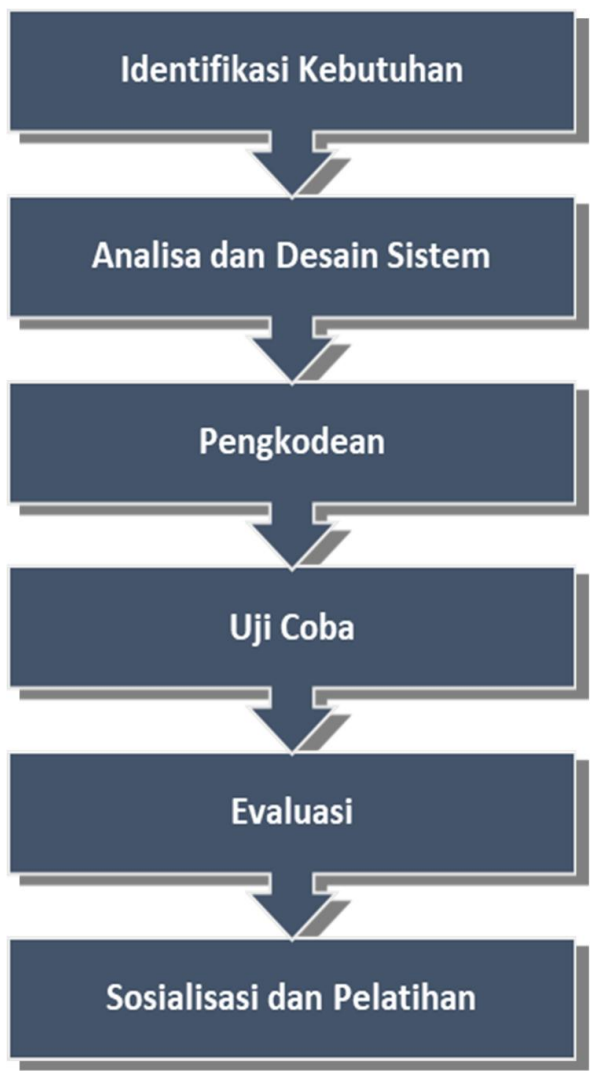

Gambar 1 Tahapan Pengembangan Website

Berikut penjelasan terkait dengan tahapan-tahapan tersebut.

1. Identifikasi Kebutuhan Sistem. Tahapan ini merupakan proses identifikasi terhadap kebutuhan sistem yang diharapkan oleh pihak PMI Kota Tarakan. Tahapan ini dilakukan melalui pertemuan (wawancara) dengan pihak PMI Kota Tarakan

2. Analisa dan Desain Sistem. Tahapan ini merupakan proses untuk melakukan analisa terhadap kebutuhan sistem yang diharapkan oleh pihak PMI Kota Tarakan. Setelah analisa dilakukan, tahap berikutnya adalah melakukan desain (perancangan) terhadap sistem yang akan dikembangkan

3. Pengkodean (Coding)

Tahapan ini merupakan tahapan untuk melakukan proses 
"coding" terhadap rancangan antarmuka yang telah dibuat ditahap sebelumnya. Pada pengembangan website profile ini digunakan PHP sebagai bahasa scripting dan MySQL sebagai database server.

PHP merupakan salah satu bahasa pemrograman yang dapat digunakan untuk mengembangkan aplikasi web yang bersifat dinamis dan interaktif. Salah satu fitur unggulan dari PHP adalah kemudahan bagi pengembang untuk dapat terhubung dan melakukan manipulasi basis data (Supaartagorn, 2011).

4. Uji Coba

Setelah proses perancangan dan pengkodean selesai dilakukan, langkah selanjutnya adalah melakukan ujicoba terhadap sistem yang telah dilakukan. Uji coba ini turut melibatkan perwakilan dari pihak PMI Kota Tarakan.

5. Evaluasi

Evaluasi merupakan salah satu tahapan akhir dari proses pengembangan sistem yang bertujuan untuk melakukan evaluasi terhadap hasil uji coba yang telah dilakukan
6. Sosialisasi

Setelah melalui proses evaluasi, tahapan berikutnya adalah melakukan sosialisasi kepada berbagai pihak yang ada di PMI Kota Tarakan terhadap sistem yang telah dikembangkan. Selain sosialisasi, juga dilakukan pelatihan terhadap pengelola sistem yang ada di PMI Kota Tarakan.

\section{Hasil dan Pembahasan}

Pada bagian ini terdapat penjelasan terkait dengan website profile PMI Kota Tarakan yang telah dikembangkan dan juga proses sosialisasi dari website tersebut.

\section{Web Profile PMI Kota Tarakan}

Halaman website profile resmi PMI Kota Tarakan yang telah dikembangkan dapat diakses pada halaman web http://pmikotatarakan. or.id. Secara keseluruhan, website tersebut berisi mengenai berbagai informasi kegiatan dari PMI Kota Tarakan. Terdapat beberapa menu yang tersedia pada website tersebut. Beberapa menu tersebut dapat dilihat pada Tabel 1 .

Tabel 1 Menu dalam Website

\begin{tabular}{|c|l|l|}
\hline No & Menu & \multicolumn{1}{c|}{ Keterangan } \\
\hline 1 & $\begin{array}{l}\text { Tentang } \\
\text { Kami }\end{array}$ & $\begin{array}{l}\text { Berisi informasi mengenai PMI Kota Tarakan, mulai dari sejarah, } \\
\text { struktur keanggotaan dan Visi Misi PMI Kota Tarakan }\end{array}$ \\
\hline 2 & $\begin{array}{l}\text { Transfusi } \\
\text { Darah }\end{array}$ & Berisi informasi mengenai tata cara transfusi darah \\
\hline 3 & Relawan & Berisi informasi mengenai PMR, KSR dan TSR \\
\hline 4 & Galeri & $\begin{array}{l}\text { Berisi dokumentasi berupa foto maupun video kegiatan PMI Kota } \\
\text { Tarakan }\end{array}$ \\
\hline 5 & $\begin{array}{l}\text { Download } \\
\text { Area }\end{array}$ & $\begin{array}{l}\text { Berisi berbagai dokumen terkait dengan PMI yang dapat di unduh oleh } \\
\text { pengunjung }\end{array}$ \\
\hline 6 & Donasi & $\begin{array}{l}\text { Berisi informasi mengenai donasi kemanusiaan yang dilakukan oleh } \\
\text { PMI }\end{array}$ \\
\hline
\end{tabular}




\begin{tabular}{|l|l|l|}
\hline 7 & $\begin{array}{l}\text { Semua } \\
\text { Agenda }\end{array}$ & $\begin{array}{l}\text { Berisi informasi semua agenda yang akan dilakukan oleh PMI Kota } \\
\text { Tarakan }\end{array}$ \\
\hline
\end{tabular}

Pada Tabel 1, dapat dilihat terdapat beberapa menu yang ada pada halaman website PMI Kota Tarakan yang telah dikembangkan. Diantaranya menu transfusi darah, relawan, galeri, download area donasi kemanusiaan, hingga menu agenda. Setiap menu ketika dipilih akan menampilkan informasi terkait dengan menu tersebut.

Sebagai contoh, ketika pengunjung memilih menu "Donasi Kemanusiaan", maka akan tampil halaman yang berisi informasi mengenai kegiatan donasi kemanusiaan yang diselenggarakan oleh PMI Kota Tarakan, begitu juga ketika pengunjung memilih menu "Transfusi Darah" maka akan tampil berbagai informasi terkait dengan transfusi darah di PMI Kota Tarakan.

Untuk tampilan halaman website yang telah dikembangkan dapat dilihat pada Gambar 2 hingga Gambar 5.

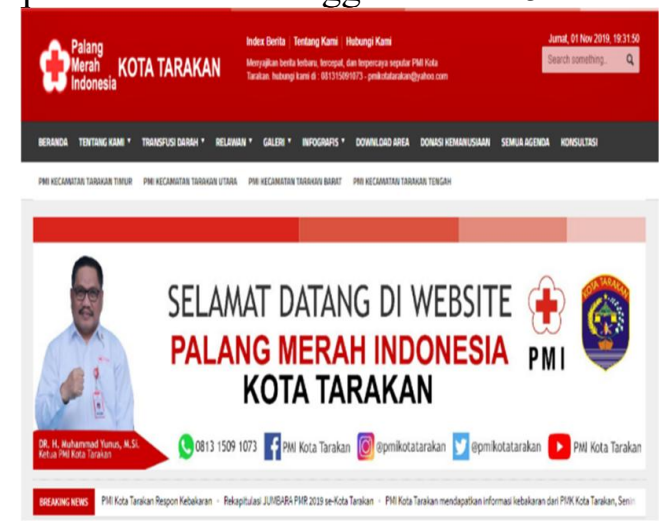

Gambar 2 Tampilan Beranda

Pada Gambar 2, merupakan tampilan beranda atau halaman awal dari website PMI Kota Tarakan yang telah dirancang.

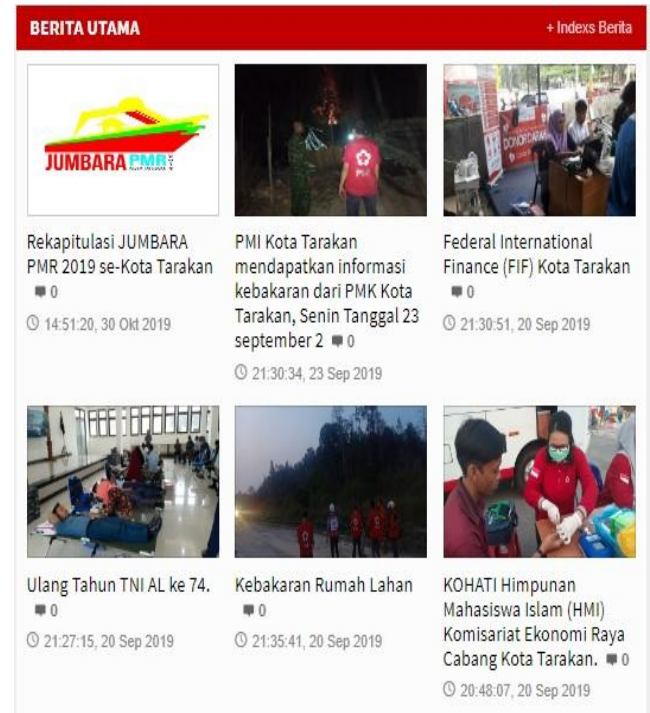

Gambar 3 Tampilan Artikel Per-PMI Kecamatan

Pada Gambar 3, dapat dilihat tampilan dari berita utama. Berita utama yang dimaksud pada website PMI Kota Tarakan merupakan kumpulan berbagai berita terbaru terkait dengan semua aktivitas atau kegiatan yang dilakukan oleh PMI Kota Tarakan.

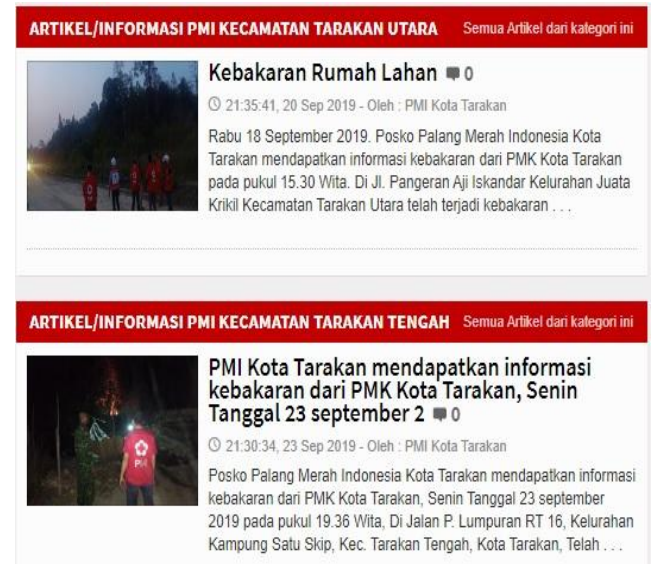

Gambar 4 Tampilan Artikel Per-PMI Kecamatan

Selanjutnya, untuk dapat melihat berbagai informasi mengenai setiap kegiatan yang dilakukan oleh PMI untuk tiap-tiap kecamatan, mulai dari Kecamatan Tarakan Timur, Tarakan Tengah, Tarakan Barat, maupun Tarakan 
Utara juga dapat dilihat pada website PMI Kota Tarakan. Hal ini dapat dilihat pada Gambar 4.

Sedangkan, untuk mengetahui apa saja berita populer atau berita yang banyak dilihat oleh pengunjung website PMI Kota Tarakan dapat dilihat pada tampilan berita populer yang terdapat pada Gambar 5. Selain itu, pada Gambar 5 terebut juga dapat dilihat komentar dari para pengunjung website. Fasilitas ini merupakan salah satu fasilitas unggulan dalam website yang telah dirancang dan sesuai dengan kebutuhan pihak PMI Kota Tarakan.

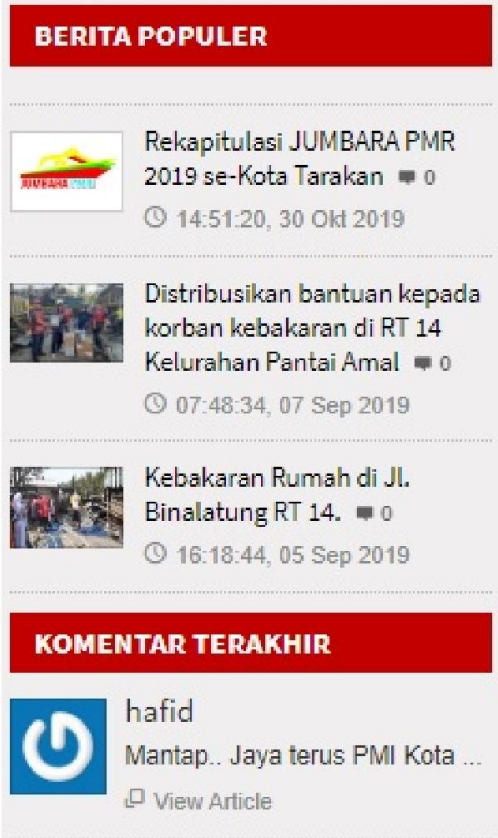

Gambar 5 Tampilan Berita Populer

Secara keseluruhan, setelah melalui berbagai tahap pengembangan mulai dari identifikasi kebutuhan yang dilakukan dengan cara observasi dan wawancara kepada pihak terkait dalam hal ini PMI Kota Tarakan, hingga tahapan ujicoba dan evaluasi website yang telah dilakukan berjalan dengan lancar. Hal ini tidak dapat terlepas dari peran berbagai pihak di PMI Kota Tarakan, yang bersifat kooperatif selama proses pengembangan website PMI Kota Tarakan tersebut.

\section{Kesimpulan dan Saran}

Terdapat beberapa hal penting yang dapat disimpulkan dari kegiatan pengabdian kepada masyarakat dalam hal pengembangan website profile bagi PMI Kota Tarakan, antara lain:

1. Website telah dikembangkan dengan menggunakan tampilan yang semenarik mungkin dan sesuai dengan kebutuhan dari pihak PMI Kota Tarakan. Hal ini dilakukan untuk memberikan kemudahan bagi pengguna maupun pengunjung website PMI Kota Tarakan tersebut

2. Website terdiri atas berbagai menu yang dapat digunakan dengan maksimal oleh pihak PMI Kota Tarakan dalam melakukan penyebaran informasi kepada masyarakat

3. Website dapat memberikan kemudahan bagi pihak PMI Kota Tarakan dalam hal memberikan informasi kepada masyarakat, khususnya terkait dengan kegiatan yang dilakukan oleh PMI Kota Tarakan.

Berdasarkan kegiatan pengabdian yang telah dilakukan juga terdapat saran yang dapat dilakukan untuk kegiatan pengabdian diwaktu yang akan datang, salah satunya adalah dengan melakukan pengembangan aplikasi yang berfokus pada kegiatan administrasi pada PMI Kota Tarakan, seperti pendataan pegawai, penggajian pegawai, presensi kehadiran pegawai, pelaporan keuangan dan lain-lain.

\section{Daftar Pustaka}

Febrianingsih, N. (2012). Keterbukaan Informasi Publik Dalam Pemerintahan Terbuka Menuju Tata Pemerintahan Yang Baik. Jurnal Rechtsvinding, 1(1), 135-156.

Hafid, M. (2018). Sejarah PMI. Retrieved October 15, 2019, from 
138 | Muhammad, et al.

http://pmikaltara.or.id/halaman/detai 1/sejarah-pmi

Santoso, H., Minarwati, \& Kholidun. (2019). Web E-Commerce Pada Toko Buku Umat Untuk Meningkatkan Evektivitas Pemasaran. Ethos : Jurnal Penelitian Dan Pengabdian Kepada Masyarakat, 7(2), 269-279.

Suhartanto, M. (2012). Pembuatan Website Sekolah Menengah Pertama Negeri 3 Delanggu Dengan Menggunakan Php Dan MySQL. Journal Speed - Sentra Penelitian Engineering Dan Edukasi, 4(1), 1-8.

Supaartagorn, C. (2011). PHP Framework For Database Management Based On MVC Pattern. International Journal of Computer Science \& Information Technology (IJCSIT), 3(2), 251-258.

Wiratmo, L. B., Irfan, N., \& Kuwatono. (2017). Website Pemerintah Daerah Sebagai Sarana Online Public Relations. Jurnal ASPIKOM, 3(2), 326-339. 